Rakenteiden Mekaniikka (Journal of Structural Mechanics)

Vol. 52, No. 4, 2019, pp. 200-221

http://rakenteidenmekaniikka.journal.fi/index

https://doi.org/10.23998/rm.76141

(C) 2019 The Authors

Open access under license CC BY 4.0

\title{
Long-term operation of a boiling water reactor pressure vessel and its internals
}

\author{
Otso Cronvall
}

Summary. This study concerns the long-term operation (LTO) of a boiling water reactor (BWR) reactor pressure vessel (RPV) and its internals. The main parts of this study are: survey on the susceptibility to degradation mechanisms, and computational time limited ageing analyses (TLAAs). The ageing of nuclear power plants (NPPs) emphasizes the need to anticipate the possible degradation mechanisms. The BWR survey on the susceptibility to these mechanisms uses the RPVs and significant internals of the Olkiluoto power plant units OL1 and OL2 as a pilot project. For the components that screened in, the potential to brittle, ductile or other degradation is determined. This was carried out by applying structural mechanics and fracture mechanics procedures. Only some most significant cases and results are presented here.

Keywords: LTO, BWR, RPV, internals, TLAA

Received 29 October 2018. Accepted 28 August 2019. Published online 31 December 2019.

\section{Introduction}

This study concerns the LTO of a BWR RPV and its internals. The main parts are:

- survey on the susceptibility to degradation mechanisms

- TLAAs for the considered components.

It is not necessary to carry out the TLAAs for all components. Some components are excluded from the TLAAs with a screening process. To do this, it is necessary to determine the component specific load induced stresses, strains and temperature distributions as well as cumulative usage factor (CUF) values.

The ageing of NPPs emphasizes the need to anticipate the possible degradation mechanisms. The BWR survey on the susceptibility to these mechanisms uses the OL1/OL2 RPVs and significant internals as a target of application.

For the components that screened-in, the TLAAs cover all significant time dependent degradation mechanisms. The main ones of these mechanisms are:

'Corresponding author: otso.cronvall@vtt.fi 
- irradiation embrittlement

- fatigue

- stress corrosion cracking (SCC)

- irradiation accelerated SCC (IASCC).

For the components that screened in, the potential to brittle, ductile or other degradation is computed. Only some most significant cases and results are presented here. According to the analysis results, the operational lifetime of the OL1/OL2 RPVs and internals can safely be extended from 40 to 60 years.

\section{On relevant degradation mechanisms affecting BWR RPV and its internals}

The relevant degradation mechanisms affecting BWR RPVs and their internals are presented in Table 1. The relevance of the degradation mechanisms is mainly based on the reports by the International Atomic Energy Agency (IAEA) [1], [2], the Electric Power Research Institute (EPRI) [3], [4], [5] and the United States Nuclear Regulatory Commission (U.S. NRC) [6], [7], [8]. These documents are based both on plant experience and laboratory test results.

Depending on the steel or alloy in question, the intensity of the external loading and environmental impact, there may be a high potential for degradation. The most important degradation modes are [2]:

- cracking

- wall thinning

- denting and pitting.

Table 1. The most relevant degradation mechanisms concerning BWR RPVs and their internals [1]-[8]. These concern brittle, ductile or other degradation.

\begin{tabular}{lll}
\hline Degradation mechanism & Degradation sub-mechanism \\
\hline Irradiation embrittlement & & \\
Thermal embrittlement & - low-cycle fatigue (LCF) \\
Fatigue & - high-cycle fatigue (HCF) \\
& - environmentally assisted fatigue (EAF) \\
Stress corrosion cracking (SCC) & - intergranular SCC (IGSCC) \\
& - transgranular SCC (TGSCC) \\
& - irradiation assisted SCC (IASCC) \\
General corrosion & - primary water SCC (PWSCC) \\
Local corrosion & - pitting corrosion \\
& - crevice corrosion \\
Flow accelerated corrosion (FAC) & \\
Creep & \\
Mechanical wear & \\
\hline
\end{tabular}




\section{Susceptibility of the OL1/OL2 RPV and its internals to degradation}

For any NPP the main characteristics and issues causing susceptibility to degradation mechanisms include:

- material type

- mechanical, thermal and dynamic loads

- manufacturing induced loads, especially weld residual stresses

- process environment

- intensity of irradiation.

To cover all these characteristics and issues properly one needs to investigate in detail the components in question and the conditions under which they reside.

The OL1/OL2 are 3rd generation ABB Atom NPP units [9] and the supplier of their RPVs was Uddcomb. Figure 1 shows the analysed RPV and internals. The original design analyses for the RPVs were done according to Article NB-3000 of an earlier edition of ASME Section III [10]. The fatigue analyses are performed in accordance with ASME section III section NB-3216.2. In 2015, the nominal power of the OL1/OL2 units was $890 \mathrm{MW}$ [11]. At the latter half of 1990's it was uprated approximately $25 \%$. The operational pressure and temperature of the OL1/OL2 RPV and internals are 70 bar and $286{ }^{\circ} \mathrm{C}$, respectively. As for the process conditions, OL1/OL2 have a normal water chemistry.

The materials of the OL1/OL2 RPV and internals are ferritic steel for the RPV base material and main nozzles, nickel-base alloys for the nozzle safe-ends, and austenitic stainless steels for the internals.

The internals determined as significant in TVO report [12] and IAEA-TECDOC1471 [1] are considered in this work. The OL1/OL2 RPV and significant internals selected for further analyses are shown in Figure 1 and listed in Table 2. Many of the considered components consist of several material regions and types of materials.

In NPPs, all systems, structures and machinery must be appointed to safety classes. This also affects to the selection of the components to be analysed. The classification shall primarily be based on deterministic methods supplemented, where necessary, by Probabilistic Risk Assessment (PRA) and expert judgement. The systems consist of defined structural and functional entities. The systems are further divided into structures and components. In Finland, the systems, structures and components of a NPP shall be grouped into the Safety Classes 1, 2, and 3 and Class EYT (non-nuclear safety), as based on their structural strength, integrity and leak-tightness required for preventing the spreading of radioactive substances. These matters are defined in the YVL Guide B.2 "Classification of systems, structures and components of a nuclear facility" [13] by the Finnish regulator STUK. The highest safety class is assigned to the most safety significant structures, components and machinery [14]. 


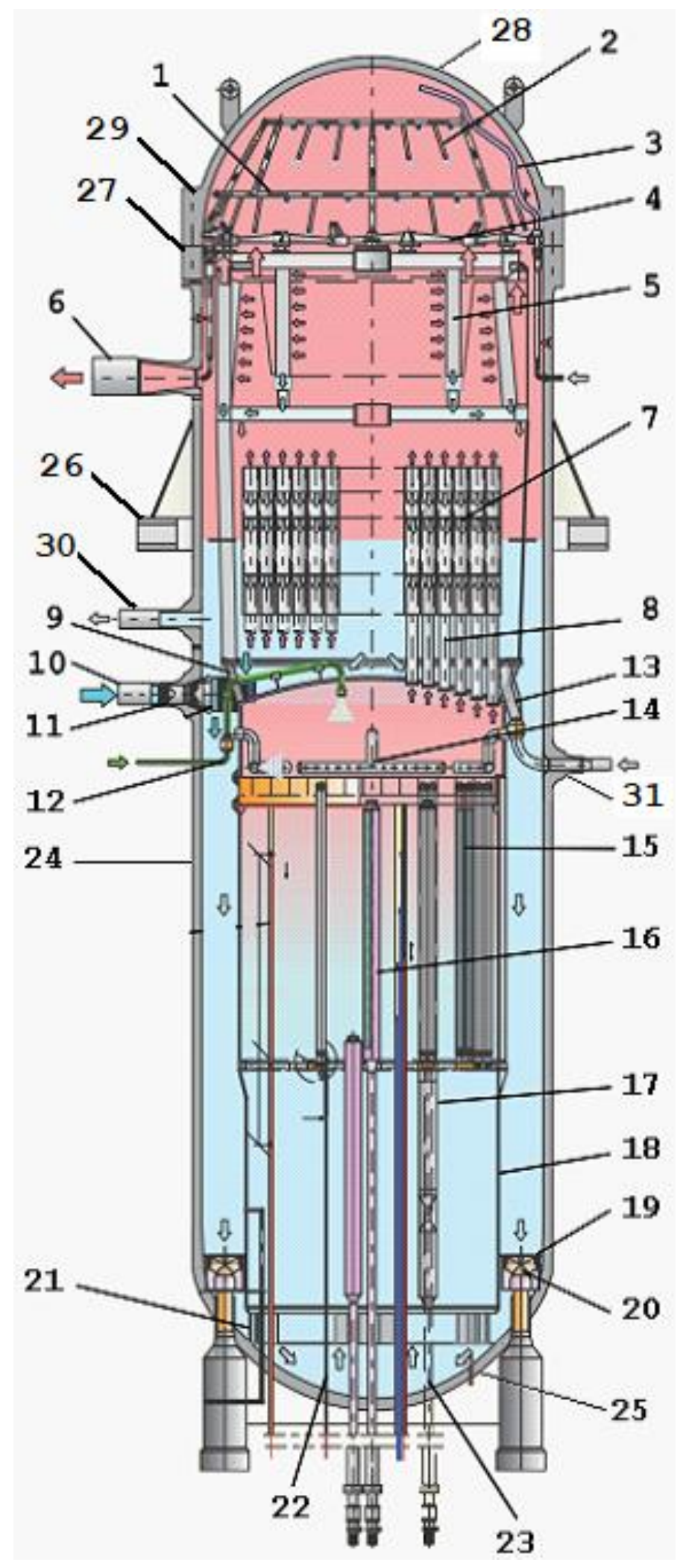

Figure 1. The OL1/OL2 RPV components and parts considered in the analyses (see Table 2 for identification). 
Table 2. The OL1/OL2 RPV components and parts considered in the analyses.

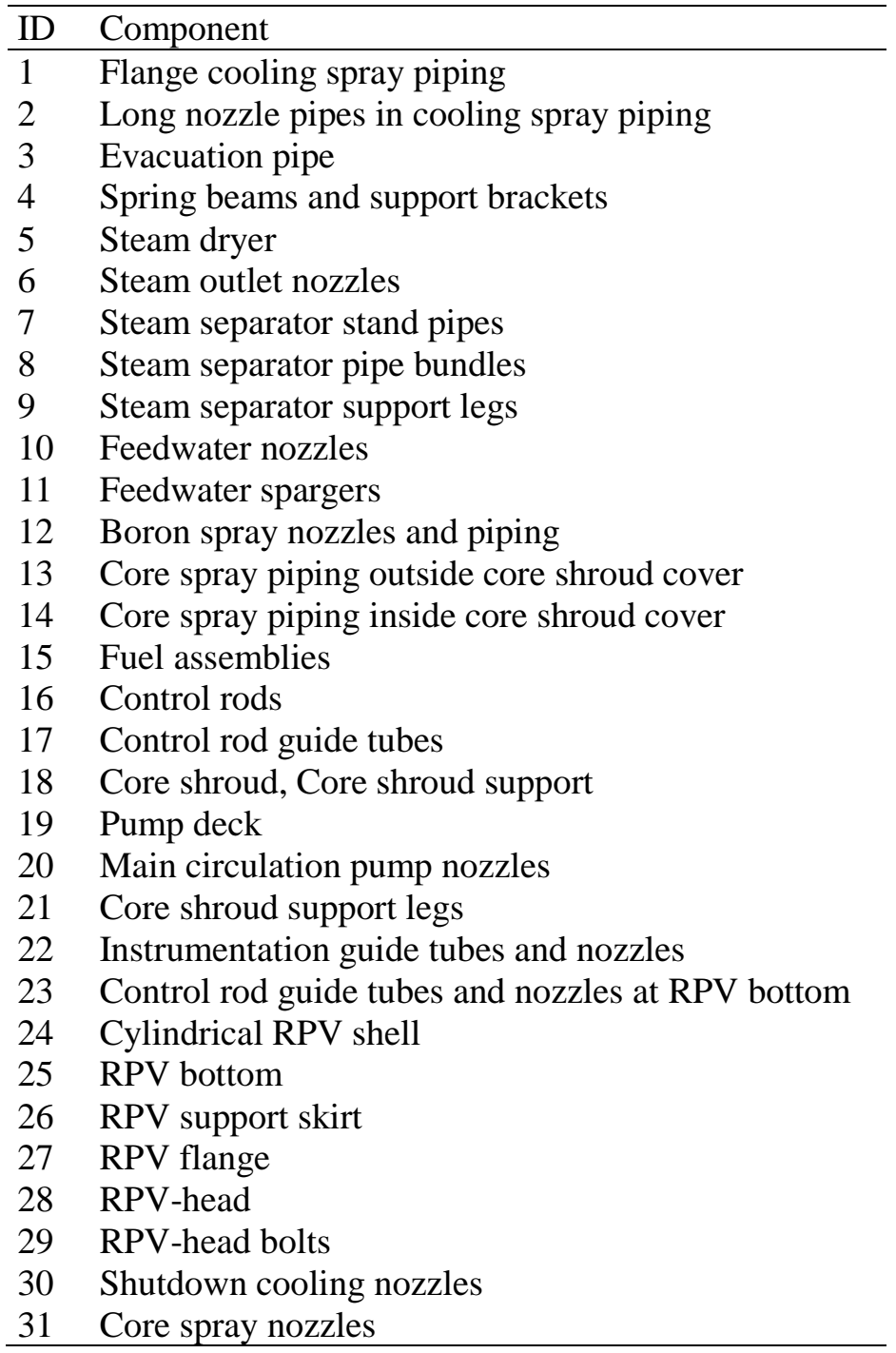

A summary on component specific susceptibility of OL1/OL2 RPV and its internals to relevant degradation mechanisms is presented in Table 3. It is based on the future dissertation [15] by the author of this article. For completeness the summary includes also fuel assemblies (ID15), but as their susceptibility to degradation mechanisms is beyond the scope of this work, the associated information is purposefully missing. It is emphasized that in most cases the presented component specific susceptibility to degradation is quite or very moderate.

The material type specific susceptibility to relevant degradation mechanisms is described after Table 3. To prepare for that the limitations and mitigating factors related to the susceptibility to the degradation mechanisms are summarised in the following. 
Table 3. Summary on component specific susceptibility of OL1/OL2 RPV and its internals to relevant degradation mechanisms. Here susceptibility is denoted with "x".

\begin{tabular}{|c|c|c|c|c|c|c|c|c|}
\hline ID & & & grad & ation & $\mathrm{mec}$ & hani & & \\
\hline & 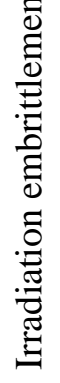 & 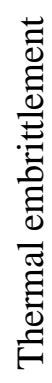 & 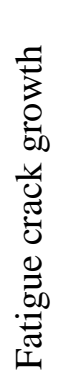 & 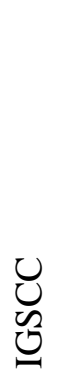 & $\begin{array}{l}\text { U } \\
\text { U }\end{array}$ & 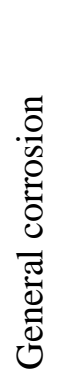 & $\underset{\Sigma}{U}$ & 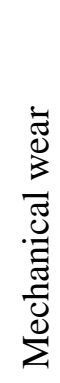 \\
\hline 1 & & & $\mathrm{x}$ & $\mathrm{x}$ & & & & \\
\hline 2 & & & $\mathrm{x}$ & $\mathrm{x}$ & & & & \\
\hline 3 & & & $\mathrm{x}$ & $\mathrm{x}$ & & & & \\
\hline 4 & & & $\mathrm{x}$ & $\mathrm{x}$ & & & & \\
\hline 5 & & & $\mathrm{x}$ & $\mathrm{x}$ & & & & \\
\hline 6 & & $\mathrm{x}$ & $\mathrm{x}$ & & & & & \\
\hline 7 & & & $\mathrm{x}$ & $\mathrm{x}$ & & & & \\
\hline 8 & & & $\mathrm{x}$ & $\mathrm{x}$ & & & & \\
\hline 9 & & & $\mathrm{x}$ & $\mathrm{x}$ & & & & \\
\hline 10 & $\mathrm{x}$ & $\mathrm{x}$ & $\mathrm{x}$ & $\mathrm{x}$ & $\mathrm{x}$ & & & \\
\hline 11 & & & $\mathrm{x}$ & $\mathrm{x}$ & $\mathrm{x}$ & & & \\
\hline 12 & & & $\mathrm{x}$ & $\mathrm{x}$ & $\mathrm{x}$ & & & \\
\hline 13 & & & $\mathrm{x}$ & $\mathrm{x}$ & $\mathrm{x}$ & & & \\
\hline 14 & & & $\mathrm{x}$ & $\mathrm{x}$ & $\mathrm{x}$ & & & \\
\hline 15 & - & - & - & - & - & - & - & - \\
\hline 16 & & & $\mathrm{x}$ & $\mathrm{x}$ & $\mathrm{x}$ & & & \\
\hline $\begin{array}{l}17 \\
\end{array}$ & & & $\mathrm{x}$ & $\mathrm{x}$ & $\mathrm{x}$ & & & \\
\hline 18 & & & $\mathrm{x}$ & $\mathrm{x}$ & $\mathrm{x}$ & & & \\
\hline 19 & & & $\mathrm{x}$ & $\mathrm{x}$ & $\mathrm{x}$ & & & \\
\hline 20 & & $\mathrm{X}$ & $\mathrm{X}$ & $\mathrm{X}$ & & & & \\
\hline 21 & & & $\mathrm{x}$ & $\mathrm{x}$ & & & & \\
\hline 22 & & & $\mathrm{x}$ & $\mathrm{x}$ & $\mathrm{x}$ & & & \\
\hline 23 & & $\mathrm{x}$ & $\mathrm{x}$ & $\mathrm{x}$ & & & & \\
\hline 24 & $\mathrm{x}$ & $\mathrm{x}$ & $\mathrm{x}$ & & & & & \\
\hline 25 & & $\mathrm{x}$ & $\mathrm{x}$ & & & & & \\
\hline 26 & & $\mathrm{x}$ & & & & & & \\
\hline 27 & & $\mathrm{x}$ & $\mathrm{X}$ & & & & & \\
\hline 28 & & $\mathrm{x}$ & $\mathrm{x}$ & & & & & \\
\hline 29 & & $\mathrm{x}$ & $\mathrm{x}$ & & & & & \\
\hline 30 & $\mathrm{x}$ & $\mathrm{x}$ & $\mathrm{x}$ & $\mathrm{x}$ & $\mathrm{x}$ & & & \\
\hline 31 & $\mathrm{x}$ & $\mathrm{x}$ & $\mathrm{x}$ & $\mathrm{x}$ & $\mathrm{x}$ & & & \\
\hline
\end{tabular}

The susceptibility to irradiation embrittlement is in practise limited to the cylinder region of the RPV and nozzles therein. This is because the gradient of the irradiation flux decreases very steeply as a function of distance from the fuel assemblies. Moreover, only ferritic steels are susceptible to irradiation embrittlement. The internals made of austenitic stainless steel at the fuel assembly region or very near to it are susceptible to IASCC. However, locally high tensional stresses are needed too for the onset of this degradation mechanism. Like in the case of IASCC, also the initiation of 
SCC requires locally high tensional stresses. The plant experience shows that such conditions exist only in those welds that have not undergone post-welding heat treatment. There are very few such welds in the OL1/OL2 RPV and internals. Even though all metallic materials are susceptible to fatigue, the yearly number of load cycles in the OL1/OL2 RPV and internals is very low. Even at the most severe conditions the degrading effect of both thermal embrittlement and general corrosion is very slow. For significant creep to occur in metallic components the operational temperatures should exceed $400{ }^{\circ} \mathrm{C}$.

The material type specific susceptibility of a BWR RPV and internals to significant degradation mechanisms is specified as follows [15]:

- irradiation embrittlement: ferritic and low alloy steels, carbon steels and associated weld metals, and low alloy RPV steels

- thermal embrittlement: the same materials as for the irradiation embrittlement as well as ferritic and martensitic stainless steels

- fatigue: all steels and alloys

- SCC and IASCC: austenitic and cast stainless steels as well as high chromium content nickel-base alloys

- general and local corrosion: all metals and alloys

- FAC: ferritic and low alloy steels, carbon steels and associated weld metals

- creep: all steels and alloys

- mechanical wear: all steels and alloys.

\section{Loads}

The BWR RPV and its internals are in contact with hot and moving liquid coolant during normal plant operations. The coolant saturation temperature corresponding to the system pressure is just below $290^{\circ} \mathrm{C}$ [11]. Internal components located in the core and in its vicinity are also exposed to fast neutron fluxes $(\mathrm{E}>1.0 \mathrm{MeV}$ ) and gamma irradiation. The operating environment inside a BWR RPV generates many loads that are considered to propagate ageing related or time dependent degradation mechanisms.

To be able to understand the BWR loading conditions, it is necessary to know about the process of normal operation. A common feature for all BWR plants is that the subcooled water enters the RPV through the feedwater nozzles. Then it goes down to the RPV bottom from where the main circulation pumps push it upwards to the core. There the water is heated up so that it changes into wet steam and its flow continues upwards to the steam dryer. The steam dryer removes the remaining liquid from the heated water [16]. After that the steam exits the RPV through the steam outlet nozzles at the saturation temperature. During operation, the nominal pressure is 70 bar. The steam produced in the reactor is directly utilized in the turbine. As to the internal configuration of the RPV, it includes an annular downcomer, where the sub-cooled feedwater mixes with the saturated liquid at the lower plenum region, while the core consists of bounded fuel elements where the phase change to steam occurs. In the OL1/OL2, the feedwater temperature is $185{ }^{\circ} \mathrm{C}$, and the live steam temperature at the turbine is $283{ }^{\circ} \mathrm{C}$, respectively [11]. The average core inlet flow velocity is approximately $2.1 \mathrm{~m} / \mathrm{s}$ [5]. 
The loads affecting the BWR RPV and its internals can be classified into the following categories:

- applied loads,

- environmental loads

- manufacturing induced loads.

Applied loads are mechanical and thermal. They are associated with normal stationary and transient plant operations. Typical examples of the latter type are start-up and shutdown. External mechanical loads include static differential pressure loadings, preloads in bolts, and hydro-dynamic forces produced by coolant flows inside the RPV. Flow induced hydro-dynamic forces can be static or oscillatory. Thermal loads are caused by temperature gradients experienced by the components, by differing thermal expansion properties of the component materials, and by restricted thermal expansion.

Major environmental loads imposed on the BWR RPV and its internals are induced by their contact with the hot and potentially corrosive coolant. The corrosiveness of the coolant is controlled primarily by the presence of dissolved oxygen in the reactor cooling water. The exposure to fast neutron fluxes $(\mathrm{E}>1 \mathrm{MeV})$ is an important environmental stressor for the RPV cylinder region and the internals.

The methods for fabricating the BWR RPV and its internals may impose loads on these components. Manufacturing loads can also promote the onset and propagation of degradation mechanisms. The conventional welding process sensitizes austenitic stainless steels, such as type 304, and makes them susceptible to corrosion. Weld residual stresses in welds and heat-affected zones (HAZs) contribute to the initiation and propagation of SCC [5]. Cold working introduces new manufacturing stresses. Plastic strains are accumulated in the component during the process and excessive plastic strain accumulation can lead to the development of cracks.

According to the later editions of the ASME Section III [10] the operating conditions are divided into four categories depending on the severity of the load transient and the number of occurrences:

a) Service Level A, corresponds to normal conditions

b) Service Level B, corresponds to upset conditions

c) Service Level C, corresponds to emergency conditions

d) Service Level D, corresponds to faulted conditions.

For most of the time the BWR plants are under $100 \%$ normal operation. That is a quasistationary loading condition, and the associated values for pressure, temperature and average flow rate are already given earlier in this section. A commonly used estimate for the yearly time in operation is 8000 hours, which corresponds to approximately 11 months. If there are no exceptional plant events, the BWR plants are shutdown once a year for refuelling and inspections.

The most common yearly transient load cases, i.e. load transients, are shutdown and start-up. For the BWR RPVs there are also other anticipated load transients. They mainly concern the feedwater system, which provides the downcomer to the RPV, but other systems produce some load transients to the RPV as well. During a load transient, temperature, pressure and flow rate alter as a function of time. All load transients start from and end to a steady-state. For instance, during shutdown temperature and pressure decrease slowly from the operational values to approximately $20^{\circ} \mathrm{C}$ and $1 \mathrm{bar}$, whereas 
during the start-up this is reversed, i.e. these load parameters return to the operational level. For some load transients the altering of the temperature is fast enough to cause temperature gradients and consequently thermal stresses to the component walls. As for the RPV bottom, the main circulation pump nozzles and control rod drive nozzles located there produce some local load transients too.

For the OL1/OL2 feedwater nozzles (ID10), 31 different anticipated significant load transients have been identified. Only 9 significant load transients have been identified for the OL1/OL2 core spray nozzles (ID31).

The loads mainly needed in the present computational analyses are the anticipated/budgeted load transients, operational conditions, flux from the fuel assemblies and weld residual stresses.

\section{Screening process}

For the NPPs the purpose of a screening process is to select the components for further analyses, especially for the computational degradation potential analyses. The objective of the degradation potential analyses is to identify the degradation mechanisms affecting the components and the increase in failure occurrences, to assess the remaining lifetime of the components, and to find suitable means to prevent or mitigate the effects of ageing degradation. To clarify, to screen in means that the component in question is included in the further analyses. And when the component screens out it means that it is dropped from the further analyses.

The degradation potential analyses should be focused on those components that are most significant from the safety point of view. They are selected with an applicable screening process. After the components are selected, the analysis methods for ageing detection and prediction are chosen.

There are a number of applicable screening process procedures for NPP components. Two significant ones are the IAEA procedure [17] and the EPRI procedure [18]. However, a specifically tailored screening process is applied here. This is because the whole analysis scope is already limited to the BWR RPV and its internals.

The screening approach applied to the considered OL1/OL2 components is a modification of that presented by EPRI in MRP-191 [18]. Therein, the stress and CUF data is used from the start. Here the screening process is divided into two steps, denoted as Step 1 and Step 2, where loads are used in Step 1 instead of stress and CUF data. As the stress and CUF analyses are laborious to perform, one purpose of the screening Step 1 is to identify the components that require those analyses. The list of components to screen in according to Step 1 will therefore be longer than would result through the MRP-191 [18] screening process. The ensuing screening Step 2, i.e. the final screening, includes both stress and CUF analyses. It is expected, that more components will screen out then, due to component specific stress and/or CUF values being below the corresponding screening values given in the EPRI report MRP-175 [19]. A flow chart of the developed screening process is presented in Figure 2. The final results from the screening process are presented after that. 
Step 1: Preliminary screening:

- takes into account base materials \& welds, geometry, load data and safety class,

- screening against most of the significant degradation mechanisms (DMs),

- data on accumulated fluence considered,

- process chemistry considered.

Step 2: Final screening:

- takes results from Step 1 as input data,

- numerical stress and CUF analyses are performed,

- screening of components from Step 1 against all significant DMs using computed stresses, CUF values and DM specific threshold data.

Figure 2. Flow chart of developed screening process for BWR RPV and its internals [15]. Here DM is degradation mechanism.

Of the 31 considered components and parts those that screened in according to the final screening are:

- ID1 Steam outlet nozzles

- ID10 Feedwater nozzles

- ID16 Control rods

- ID17 Control rod guide tubes

- ID18 Core shroud, Core shroud support

- ID19 Pump deck

- ID21 Core shroud support legs

- ID22 Instrumentation guide tubes and nozzles

- ID23 Control rod guide tubes and nozzles at RPV bottom

- ID24 Cylindrical RPV shell

- ID30 Shutdown cooling nozzles

- ID31 Core spray nozzles.

Thus, altogether 12 components and parts screened in. Table 4 shows the more detailed results from the final screening. Therein the column "Screening result (In/Out)" at the right side shows the final screening results. In that column decision "In" means that the component in question screened in and is included in the further degradation potential analyses. When the decision is "Out" it means that the component screened out and is dropped from the further degradation potential analyses. Table 4 also contains the results from the screening process Step 1, through which 15 of the considered 31 components and parts are already screened out. 
Table 4. The results from the final screening for the considered OL1/OL2 components/parts [15]. Screening criterion is denoted with "SCR". For the names of the components and parts, see Table 2.

\begin{tabular}{|c|c|c|c|c|c|c|c|c|c|}
\hline \multirow[t]{2}{*}{ ID } & \multicolumn{8}{|c|}{ Degradation mechanism } & \multirow[b]{2}{*}{ 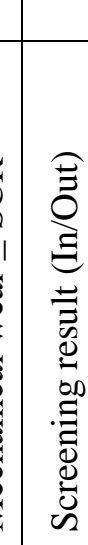 } \\
\hline & 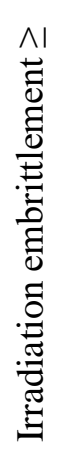 & 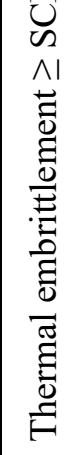 & 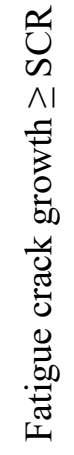 & 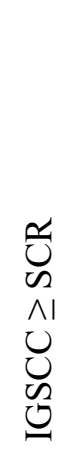 & 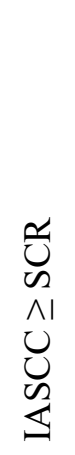 & 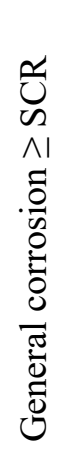 & 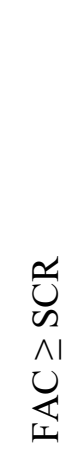 & 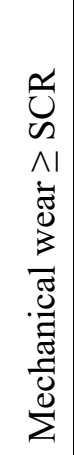 & \\
\hline 4 & No & No & No & No & No & No & No & No & Out \\
\hline 6 & No & Yes & No & No & No & No & No & No & In \\
\hline 9 & No & No & No & No & No & No & No & No & Out \\
\hline 10 & Yes & Yes & Yes & Yes & No & No & No & No & In \\
\hline 11 & No & No & Yes & Yes & No & No & No & No & Out \\
\hline 14 & No & No & No & No & No & No & No & No & Out \\
\hline 16 & No & No & Yes & No & Yes & No & No & No & In \\
\hline 17 & No & No & Yes & No & Yes & No & No & No & In \\
\hline 18 & No & No & Yes & No & No & No & No & No & In \\
\hline 19 & No & No & Yes & Yes & No & No & No & No & In \\
\hline 21 & No & No & Yes & Yes & No & No & No & No & In \\
\hline 22 & No & No & No & No & Yes & No & No & No & In \\
\hline 23 & No & Yes & Yes & Yes & No & No & No & No & In \\
\hline 24 & Yes & Yes & Yes & No & No & No & No & No & In \\
\hline 30 & Yes & Yes & Yes & Yes & No & No & No & No & In \\
\hline 31 & Yes & Yes & Yes & Yes & No & No & No & No & In \\
\hline
\end{tabular}

\section{Computational approaches, tools and analyses}

The degradation potential analyses with fracture mechanics need stresses and strains through component walls as part of the necessary input data.

The stress/strain analyses are carried out with finite element (FE) codes ANSYS [20] and Abaqus [21] as well as by using analytical equations. Part of the FE models and most FE analyses are done by the author of this work. The rest of the FE models are prepared by VTT and FS Dynamics Sweden AB.

The degradation potential analyses are in most cases carried out with fracture mechanics based analysis code VTTBESIT. This code comprises parts developed by VTT [22], [23] and by IWM [24], [25], [26], the latter being the Fraunhofer-Institut für Werkstoffmechanik, in Germany. In some cases, handbook solutions are used too, such as those in the R6 Method, Rev. 4 [27] and those by Zahoor [28]. VTTBESIT computes 
the mode I stress intensity factor, $K_{I}$, values over the crack postulate fronts. This is based on the weight/influence function method. Solutions are provided for "infinite" and semi-elliptic surface crack postulates in straight plates and hollow cylinders. VTTBESIT calculates the crack growth as a sequence of increments until some predefined ending criterion is reached. Two crack growth models are provided in the analysis code:

- the Paris-Erdogan equation [29] for fatigue crack growth (FCG)

- the rate equation [30] for SCC.

Some representative examples of the used FE models are shown in the following. Figure 3 shows the FE model of the feedwater nozzle prepared by VTT [31]. Figure 4 shows an overview of the FE sub-models prepared by FS Dynamics [32].

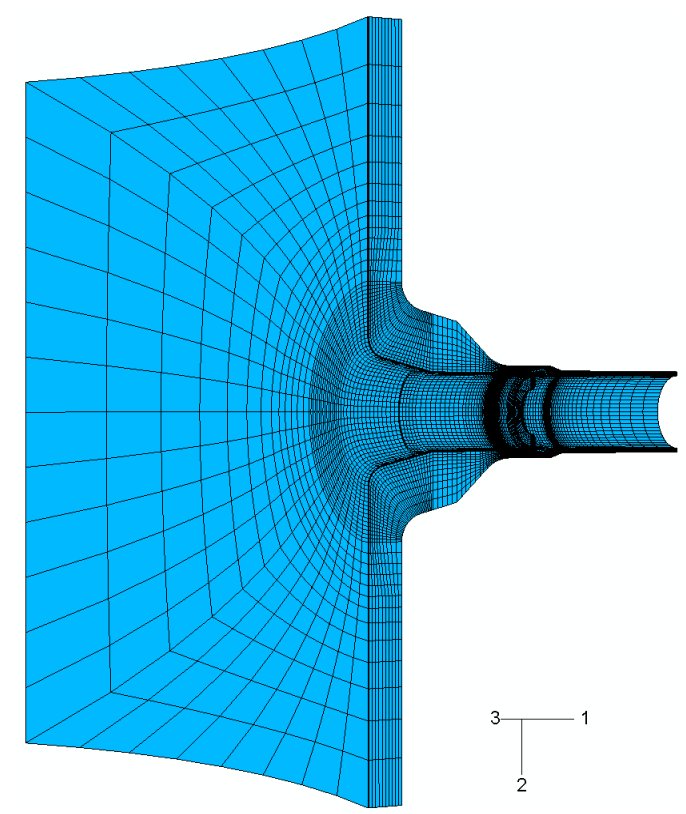

Figure 3. The OL1/OL2 feedwater nozzle FE model prepared by VTT [31].

\section{Degradation potential and criticality analyses}

The degradation potential and criticality analyses for the components and parts that screened in according to the final screening are described in the following. This is limited only to three components. However, these analyses are carried out for all components that screened in, as described in detail in ref. [15].

The degradation potential and criticality analyses concern the assessment of time dependent propagation of the degradation mechanisms that the components in question are susceptible to. These are also called TLAAs. This includes also the assessment of the critical flaw size for the structural detail in question. Typically, the considered critical states are leak and break. Due to high safety demands, maximum allowable flaw sizes have been defined for NPP components in codes and norms. For instance, according to the ASME Section XI [33] the maximum allowable crack depth through wall is $75 \%$ of the wall thickness for narrow cracks in pipes and nozzles, whereas for 
longer cracks it is less than that. The considered initial flaws can be either existing, i.e. detected in inspections and then measured, or postulated.

Examples of the performed degradation potential and criticality analyses are described in the following for:

- feedwater nozzles

- core shroud

- cylindrical RPV shell.

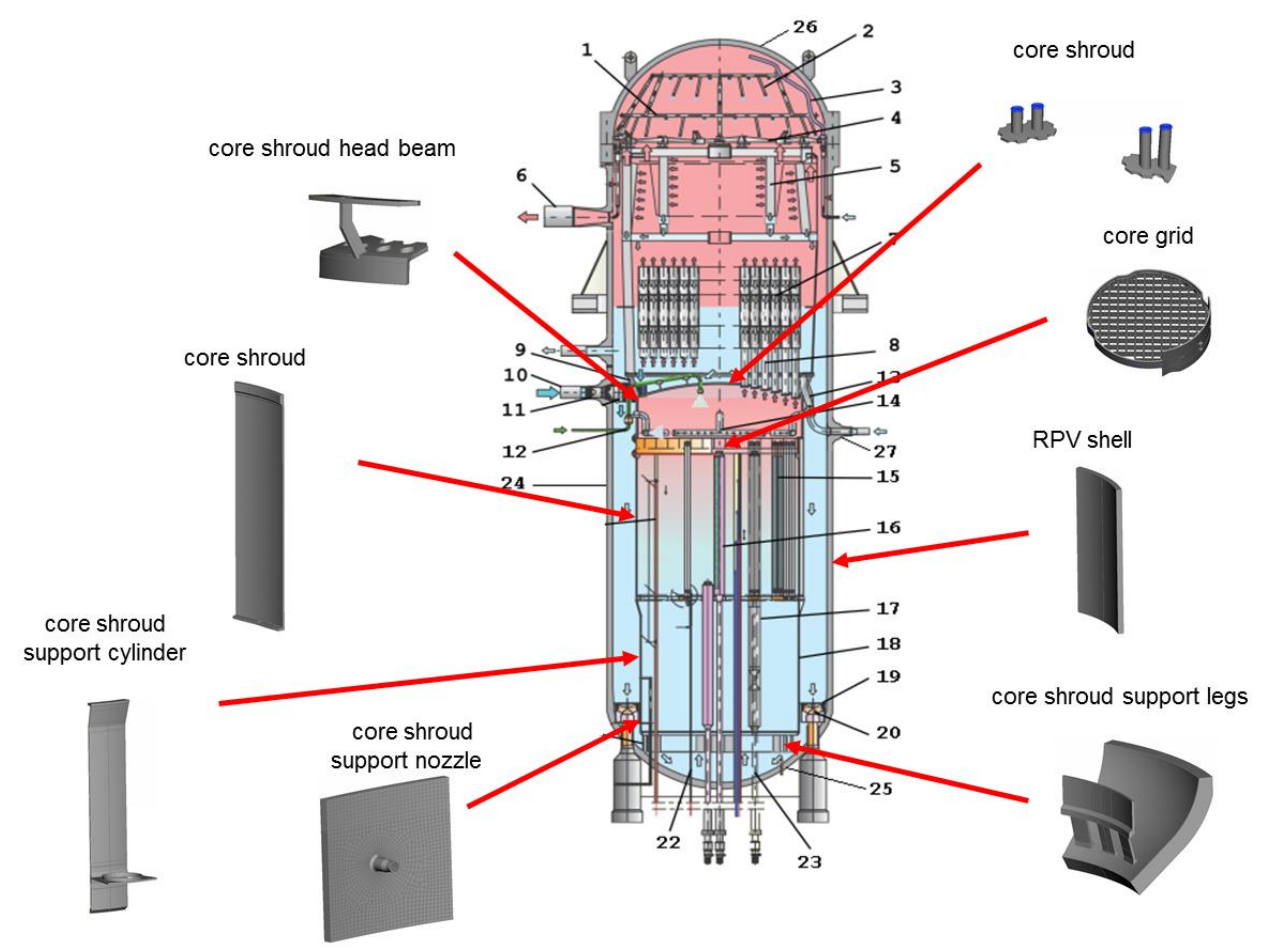

Figure 4. An overview of the FE sub-models prepared by FS Dynamics [32].

\section{Feedwater nozzles}

The Feedwater nozzles are affected by altogether four degradation mechanisms: irradiation embrittlement, thermal embrittlement, IGSCC and LCF. The analyses concerning IGSCC and LCF for 60 years of operation are described in the following. At the location of the Feedwater nozzles the irradiation flux from the fuel assemblies is already so low that the effect of irradiation embrittlement is very small even after 60 years in operation.

The steps of the TLAAs for IGSCC and LCF in the nozzle/safe-end weld are as follows:

- collection of input data

- selection of crack postulates

- computation of crack growth for 60 years of plant operation

- determination of critical crack sizes

- presentation of the TLAA results. 
The wall thickness at the weld location is approximately $35 \mathrm{~mm}$. The overall geometry of the Feedwater nozzle is presented in Figure 1, see ID10. The FE model of the Feedwater nozzle is presented in Figure 3. The weld material is of an alloy that is regarded as susceptible to SCC. The properties for this weld material are taken from handbooks. For the IGSCC analyses the stress data is taken from a confidential FE analysis report [34], including FE simulated weld residual stresses. Through the middle of the weld the FE simulated total stresses vary in the axial direction between approximately -200 and $270 \mathrm{MPa}$ and in the circumferential direction between approximately 0 and $380 \mathrm{MPa}$, respectively. For the LCF analyses the stress cycle data is taken from a confidential FE analysis report [35]. The conservatively budgeted yearly number of load cycles is less than 60 . Note, that for the majority of these load cycles the stress ranges remain quite low.

The considered flaw postulates are axially and circumferentially orientated semielliptic cracks opening to the inner surface. In the IGSCC analyses the depth of the initial cracks varies from 1.0 to $5.0 \mathrm{~mm}$ and the corresponding length from 6.0 to 14.4 $\mathrm{mm}$, respectively. For most initial cracks depth divided length is $1 / 6$. It is assumed that the initial cracks exist/nucleate from the start of the plant operation. The assumed yearly time in operation is 8000 hours, corresponding to approximately 11 months. The values for material and environment specific parameters in the SCC rate equation and FCG Paris-Erdogan equation are taken from refs. [29] and [30], respectively.

The results from the IGSCC analyses are shown in Figures 5 and 6 . The axially orientated crack cases are 1a, 1b, 1c, 1d and 1e. The IGSCC results for the circumferentially orientated crack case 2 are not shown because the crack growth was extremely small. No LCF analysis results are shown because for all considered initial cracks the crack growth is negligible. In the legend of Figure 6 EOL is end-of-life, i.e. the maximum allowable crack depth according to the ASME Section XI [33].

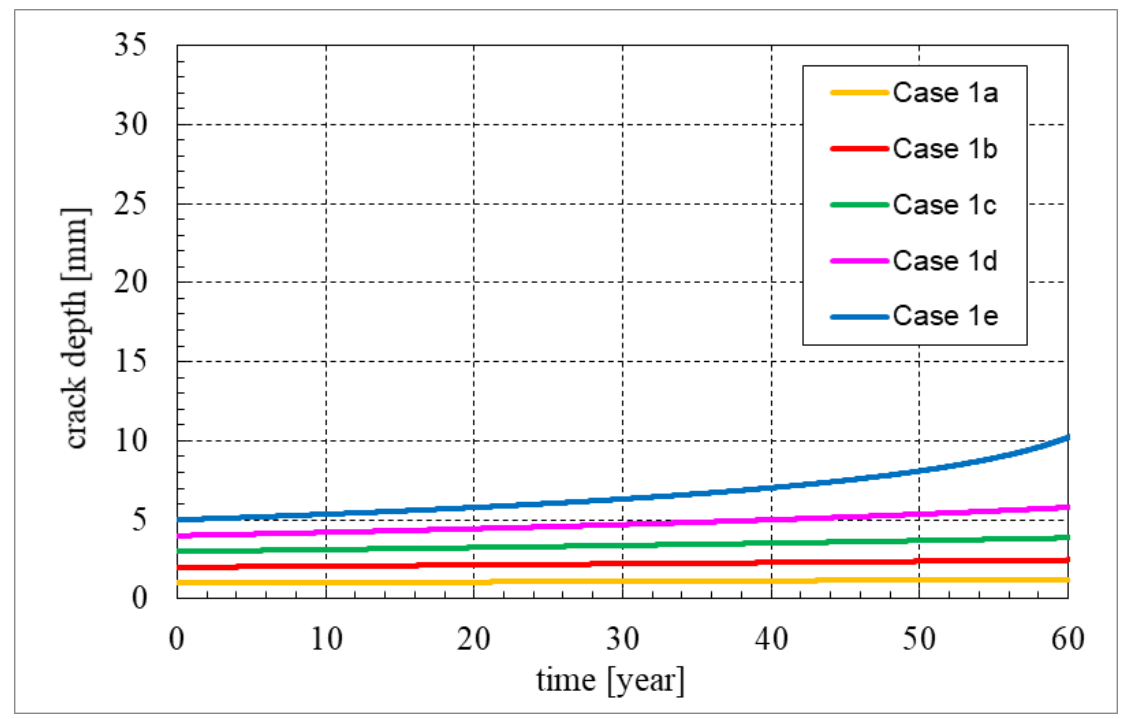

Figure 5. The results from the IGSCC analyses for axially orientated Cases 1a (smallest) to 1e (largest), showing time dependent crack growth [15]. 


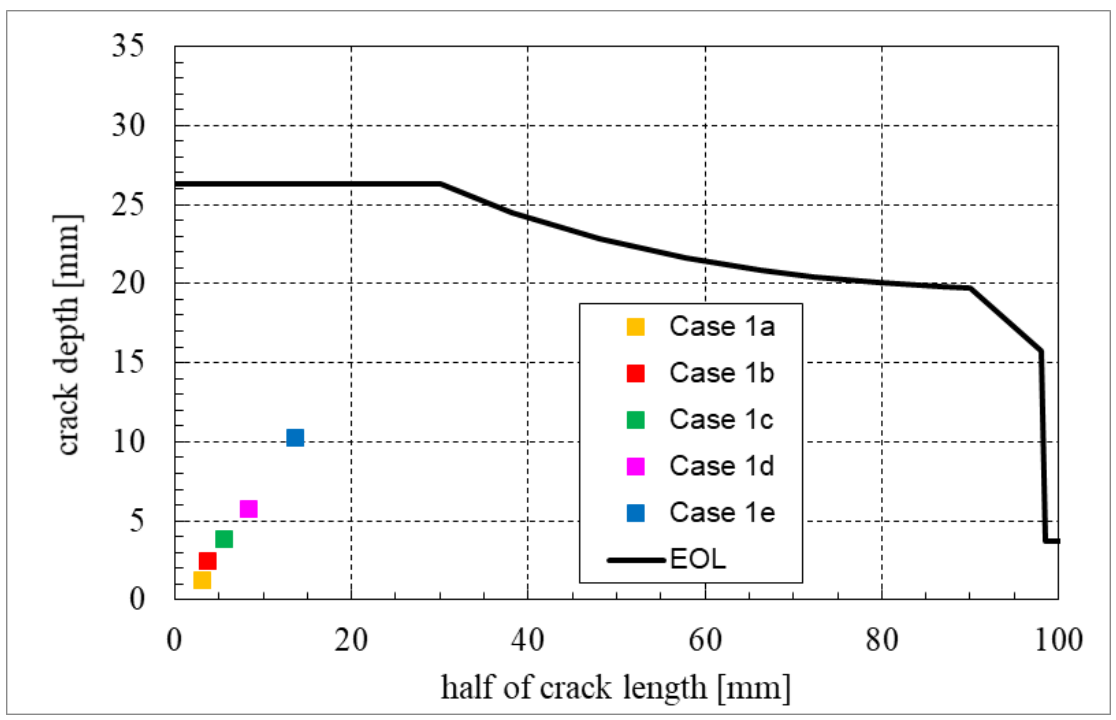

Figure 6. The results from the IGSCC analyses for axially orientated Cases 1a (smallest) to 1e (largest), showing crack growth after 60 years and EOL crack sizes [15].

\section{Core shroud}

The Core shroud is affected by one degradation mechanism: LCF. The analysis concerning LCF for 60 years of operation is described in the following. This analysis concerns the weld near the top of the Core shroud wall. For IASCC the experienced fluence after 60 years in operation is below the screening value, and for both IASCC and IGSCC the stresses are below the screening value. The steps of the TLAA for LCF in the Core shroud top weld are as follows:

- collection of input data

- selection of crack postulates

- computation of crack growth for 60 years of plant operation

- determination of critical crack sizes

- presentation of the TLAA results.

The wall thickness of the weld is approximately $25 \mathrm{~mm}$. The weld material is alloy Inconel 182, while the base material is of austenitic stainless steel. The overall geometry of the Core shroud is presented in Figure 1, see ID18. The properties for the considered materials are taken from handbooks. For the LCF analyses the stress cycle data was mainly taken from a confidential FE analysis report [38]. Through the middle of the weld the computed total stress ranges stayed below $100 \mathrm{MPa}$ both in the axial and circumferential direction. The conservatively budgeted yearly number of load cycles is a bit more than 20 . Note, that for the majority of these load cycles the stress ranges are quite low.

The considered flaw postulate is an axially orientated semi-elliptic crack opening to the outer surface. In the analyses the initial depth and length of the cracks vary from 1.0 to $5.0 \mathrm{~mm}$ and the corresponding length from 6.0 to $30.0 \mathrm{~mm}$, respectively. The aspect ratio of all initial cracks is $1 / 3$. It is assumed that the initial cracks exist/nucleate from 
the start of the plant operation. The assumed yearly time in operation is 8000 hours, corresponding to approximately 11 months.

The values for material and environment specific parameters in the FCG ParisErdogan equation were taken from ref. [37]. The resulting crack depths from the FCG analyses are shown in Figure 7. As the occurrence times of the load cycles are known, the crack growth results are expressed as a function of time.

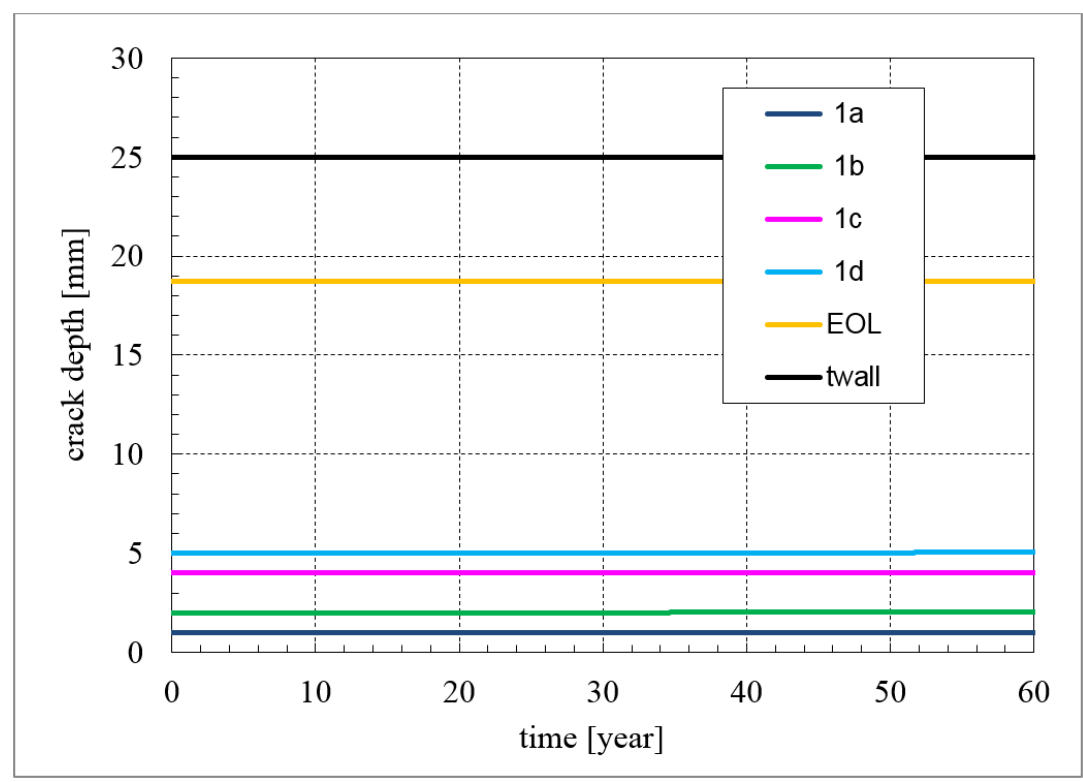

Figure 7. The results from the LCF analyses for axially orientated Cases 1a (smallest) to 1d (largest), showing time dependent crack growth [15].

\section{Cylindrical RPV shell}

The Cylindrical RPV shell is affected by altogether three degradation mechanisms: irradiation embrittlement, thermal embrittlement and LCF. Only the analysis concerning irradiation embrittlement for 60 years of operation is described in the following. This analysis concerns the ferritic base material. Note, that there is a thin cladding of austenitic stainless steel at the inner surface. According to the confidential report [39] the accumulated maximum fluence for the RPV shell inner surface after 60 years in operation is approximately $8.3 \mathrm{E}+17 \mathrm{n} / \mathrm{cm}^{2}$ (number of fast neutrons per square $\mathrm{cm}$ ).

The steps of the TLAA for irradiation embrittlement in the Cylindrical RPV shell are as follows:

- collection of input data

- assessment of irradiation embrittlement induced shift of reference nil-ductility temperature, $R T_{N D T}$

- computation of irradiation embrittlement adjusted $R T_{N D T}$

- computation of fracture toughness, $K_{I c}$, corresponding to irradiation embrittlement adjusted $R T_{N D T}$

- selection of crack postulate

- computation of $K_{I}$ values over the front of the selected crack postulate 
- determination of the criticality of the used crack postulate in combination with the irradiation embrittlement adjusted $R T_{N D T}$

- presentation of the TLAA results.

The total wall thickness of the RPV shell is approximately $140 \mathrm{~mm}$. The base material is ferritic steel ASTM 533 Grade B, Class 1. The overall geometry of the RPV shell is presented in Figure 1, see ID24. The properties for the considered material are taken from handbooks. For the irradiation embrittlement analyses the stress data is taken from two confidential FE analysis reports [40], [41]. The computed total through-wall stresses varied in the circumferential direction between approximately 360 and 130 MPa.

The initial $R T_{N D T}$ value is taken as an average of the reported data [42]. The shift of the $R T_{N D T}$ value after 60 years of operation is computed according to the U.S. Regulatory Guide 1.99, Rev 2 [43]. Based on the adjusted $R T_{N D T}$ value, the $K_{I c}$ values after 60 years in operation are computed according to Appendix G of ASME Section XI [33].

The considered flaw postulate is an axially orientated semi-elliptic crack opening to the inner surface. Here the reference crack according to Appendix G of ASME Section XI [33] is used: for section thicknesses of $102 \mathrm{~mm}$ to $305 \mathrm{~mm}$, the crack has a depth of $1 / 4$ times the section thickness and a length of $3 / 2$ times the section thickness.

The computed $K_{I c}$ values at the start of the operation and after 60 years of operation for the RPV shell are shown in Figure 8. According to the computational results the maximum $K_{I}$ value caused by mechanical loads, $K_{I m}$, is $79 \mathrm{MPa} \sqrt{\mathrm{m}}$ and that caused by thermal loads, $K_{I t}$, is $2 \mathrm{MPa} \sqrt{\mathrm{m}}$, respectively. According to Appendix G of ASME Section XI [33] the following condition must be fulfilled for the reference crack:

$$
2 K_{I m}+K_{I t}<K_{I c}
$$

At the operational conditions, this condition is well fulfilled, as according to the computational results [15]: $2 K_{I m}+K_{I t}=95 \mathrm{MPa} \sqrt{ }$ m, whereas $K_{I c}=203 \mathrm{MPa} \sqrt{\mathrm{m}}$.

\section{Summary}

This study concerns the LTO of BWR RPVs and their internals. It includes considering the OL1/OL2 units as a pilot project. The main parts of this study are: a survey on susceptibility to degradation mechanisms, and computational TLAAs. The following issues are covered:

- relevant degradation mechanisms affecting BWR RPV and its internals

- susceptibility of the OL1/OL2 RPV and its internals to degradation

- loads

- screening process

- degradation potential and criticality analyses for the OL1/OL2 RPV and its internals.

According to the conservative TLAA results the degradation in terms of crack growth is in most cases very or extremely slow. In the few cases with faster crack growth the cracks would be detected in the inspections well before they grow to any critical size. 


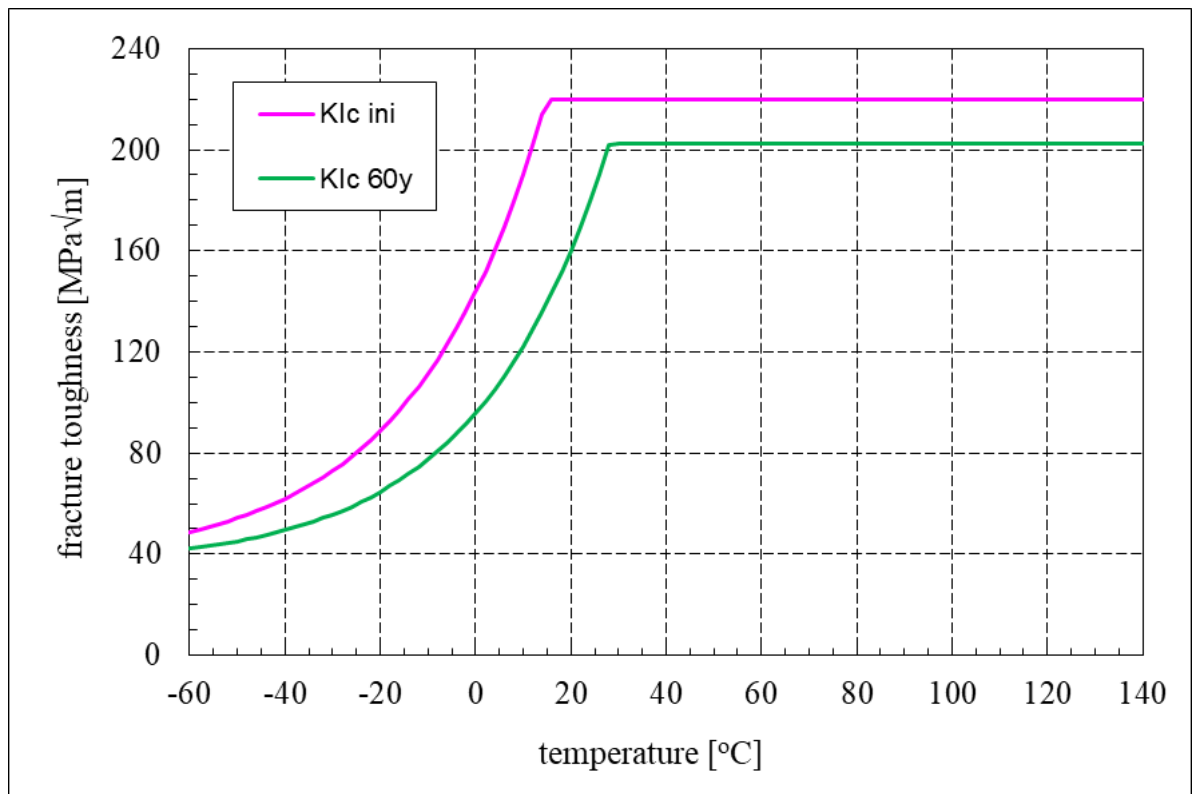

Figure 8. The computed $K_{I c}$ values at the inner surface of the RPV shell base material. In the legend ini is the initial state and 60y the aged state after 60 years in operation [15].

\section{Conclusions}

The main purpose here is to conclude that this work provides the technical background for the LTO from 40 to 60 years to the OL1/OL2 RPV and its internals. This is done based on the results from the performed TLAAs.

Firstly, it is concluded that the survey concerning the susceptibility of the BWR RPV and its internals to various degradation mechanisms is thorough enough. All possible degradation mechanisms are taken into account.

It is concluded that the scope of the considered components is sufficient. In addition to the OL1/OL2 RPVs, all their significant internals are covered.

The conclusion concerning the applied component screening process is that it is technically sound and detailed enough. It is in line with the screening processes by IAEA and EPRI.

Based on the TLAA results, it is concluded that the operational lifetime of the OL1/OL2 RPV and its internals can be safely continued from 40 to 60 years.

\section{Nomenclature}

\section{Symbols}

$K_{I} \quad$ Mode I stress intensity factor

[MPaVm]

$K_{\text {Ic }} \quad$ Fracture toughness $\quad[\mathrm{MPaVm}]$

$K_{I m} \quad K_{I}$ due to mechanical loads $\quad[\mathrm{MPaVm}]$ 
$\begin{array}{lll}K_{I t} & K_{I} \text { due to thermal loads } & {[\mathrm{MPaVm}]} \\ R T_{N D T} & \text { Reference nil-ductility temperature } & {\left[{ }^{\circ} \mathrm{C}\right]}\end{array}$

\section{Abbreviations}

$\begin{array}{ll}\text { ASME } & \text { American Society of Mechanical Engineers } \\ \text { Aspect ratio } & \text { Ratio of crack depth and half of its length } \\ \text { BWR } & \text { Boiling water reactor } \\ \text { EAF } & \text { Environmentally assisted fatigue } \\ \text { EPRI } & \text { Electric Power Research Institute } \\ \text { FCG } & \text { Fatigue crack growth } \\ \text { FE } & \text { Finite element } \\ \text { HCF } & \text { High-cycle fatigue } \\ \text { IAEA } & \text { International Atomic Energy Agency } \\ \text { IASCC } & \text { Irradiation accelerated SCC } \\ \text { IGSCC } & \text { Intergranular SCC } \\ \text { LCF } & \text { Low-cycle fatigue } \\ \text { LTO } & \text { Long-term operation } \\ \text { NPP } & \text { Nuclear power plant } \\ \text { OL1/OL2 } & \text { NPP units OL1 and OL2 of TVO } \\ \text { PWSCC } & \text { Primary water SCC } \\ \text { RPV } & \text { Reactor pressure vessel } \\ \text { SCC } & \text { Stress corrosion cracking } \\ \text { TGSCC } & \text { Transgranular SCC } \\ \text { TLAA } & \text { Time limited ageing analysis } \\ \text { U.S. NRC } & \text { United States Nuclear Regulatory Commission }\end{array}$

\section{References}

[1] Assessment and management of ageing of major nuclear power plant components important to safety: BWR pressure vessel internals. IAEA-TECDOC-1471, International Atomic Energy Agency (IAEA), Vienna, Austria, October 2005. https://www-pub.iaea.org/MTCD/Publications/PDF/te_1471_web.pdf

[2] Safety aspects of nuclear power plant ageing. IAEA-TECDOC-540, International Atomic Energy Agency (IAEA), Vienna, Austria, 1990. https://wwwpub.iaea.org/MTCD/publications/PDF/te_540_prn.pdf

[3] EPRI Materials Degradation Matrix, Revision 3. EPRI Project Manager: Lian, T. EPRI Report 3002000628, Electric Power Research Institute (EPRI), California, USA, May 2013.

[4] BWR Reactor Pressure Vessel Internals - License Renewal Industry Report; Revision 1. EPRI Report TR-103839, Electric Power Research Institute (EPRI), USA, July 1994.

[5] J. Mitman (Project Manager). Revised Risk Informed In-Service Inspection Evaluation Procedure, Rev. A-B. Final Report EPRI TR-112657, Electric Power Research Research Institute (EPRI). US, December 1999. 
[6] J. Busby et al. Expanded Materials Degradation Assessment (EMDA), Volume 1: Executive Summary of EMDA Process and Results. Report NUREG/CR-7153, Vol. 1, United States Nuclear Regulatory Commission (U.S. NRC), October 2014. https://www.nrc.gov/docs/ML1427/ML14279A321.pdf

[7] K. H. Luk. Boiling-Water Reactor Internals Aging-Degradation Study Phase 1. Report NUREG/CR-5754, United States Nuclear Regulatory Commission (U.S. NRC), 1993. https://www.osti.gov/servlets/purl/10182155

[8] C. L. Smith, V. N. Shah, T. Kao, G. Apostolakis. Incorporating Aging effects into Probabilistic Risk Assessment - A Feasibility Study Utilizing Reliability Physics Models. Report NUREG/CR-5632, U.S. Nuclear Regulatory Commission (U.S. NRC), 2001. https://www.nrc.gov/docs/ML0124/ML012490206.pdf

[9] T. Graae. Repair and replacement of reactor internals for plant life extension. Nuclear Engineering and Design, 185 (1998) 319-334.

[10] ASME Boiler and Pressure Vessel Code, Section III, Division 1. American Society of Mechanical Engineering (ASME).

[11] Nuclear power plant units Olkiluoto 1 and Olkiluoto 2. Teollisuuden Voima Oyj (TVO), PDF Publication in English, from http://www.tvo.fi, 24 November 2011.

[12] P. Lemettinen. OL1/OL2 Power Uprate - Risk Survey for Flow-induced Vibrations of RPV Internals. TVO Report 156094, Teollisuuden Voima Oyj (TVO), Eurajoki, Finland, 15.8.2016.

[13] Classification of Systems, Structures and Components of a Nuclear Facility. Guide YVL B.2, Radiation and Nuclear Safety Authority of Finland (STUK), 15 November 2013.

[14] L. Saarelainen. OL1/OL2 - Luokitusasiakirja. Document 136866, Rev. 2, Teollisuuden Voima Oyj (TVO), Finland, February 2013. (in Finnish)

[15] O. Cronvall. Susceptibility of Boiling Water Reactor Pressure Vessel and Its Internals to Degradation. Draft of a doctoral dissertation, Espoo, Finland, 05.09.2018.

[16] State of the Art Report on Boiling Water Reactor Stability (SOAR on BWRs). Report NEA/CSNI/R(96)21, OECD Nuclear Energy Agency (OECD/NEA), France, January 1997. https://www.oecd-nea.org/nsd/docs/1996/csni-r1996-21.pdf

[17] Methodology for the Management of Ageing of Nuclear Power Plant Components Important to Safety. Technical Reports Series No. 338, International Atomic Energy Agency (IAEA), Vienna, 1992. https://wwwpub.iaea.org/MTCD/Publications/PDF/TRS338_web.pdf

[18] H. T. Tang. Materials Reliability Program: Screening, Categorization, and Ranking of Reactor Internals Components for Westinghouse and Combustion Engineering PWR Design (MRP-191). Technical Report 1013234, Electric Power Research Institute (EPRI), California, U.S., November 2006.

[19] Materials Reliability Program: PWR Internals Material Aging Degradation Mechanism Screening and Threshold Values (MRP-175), EPRI Report 1012081, Electric Power Research Institute (EPRI), USA, 2005.

[20] ANSYS Theory Manual, Release 17.0. ANSYS Inc., U.S., 2016.

[21] Abaqus Theory Manual, Version 6.14-1. Dassault Systemes, France, 2014. 
[22] A. Vepsä. Verification of the stress intensity factors calculated with the VTTBESIT software. Technical Research Centre of Finland (VTT), Research Group Structural Integrity, Research Report TUO72-044578.

[23] O. Cronvall, A. Vepsä. Further development and validation of probabilistic analysis application VTTBESIT. VTT Report VTT-R-01837-12, Technical Research Centre of Finland (VTT), Espoo, Finland, March 2012.

[24] I. Varfolomeyev et al. BESIF 1.0: Stress Intensity Factors for Surface Cracks under 2D Stress Gradients. IWM-Report T 14/96, Fraunhofer-Institut für Werkstoffmechanik (IWM), July 1996.

[25] M. Busch et al. KI-Factors and Polynomial Influence Functions for Axial and Circumferential Surface Cracks in Cylinders. IWM-Report T 18/94, FraunhoferInstitut für Werkstoffmechanik (IWM), October 1994.

[26] M. Busch et al. Polynomial Influence Functions for Surface Cracks in Pressure Vessel Components. IWM-Report Z 11/95, Fraunhofer-Institut für Werkstoffmechanik (IWM), January 1995.

[27] R6 Method - Assessment of the Integrity of Structures containing Defects, Revision 4. 2004 update of 2001 edition. British Energy (BE).

[28] A. Zahoor. Ductile Fracture Handbook, Volume 2. Report EPRI NP-6301-D, V2, Electric Power Research Institute (EPRI), California, U.S, October 1990.

[29] P.C. Paris, F. Erdogan. A Critical Analysis of Crack Propagation Laws. Journal of Basic Engineering, 85 (1960), 528-534.

[30] W.S. Hazelton, W.H. Koo. Technical Report on Material Selection and Processing Guidelines for BWR Coolant Pressure Boundary Piping: Final Report NUREG0313, Rev. 2-F, U.S. Nuclear Regulatory Commission (U.S. NRC), January 1988.

[31] O. Cronvall. OL1 and OL2 - Reactor Pressure Vessel crack sensitivity analyses 312 -nozzles, Rev. 1. Report VTT-R-04821-07, Technical Research Centre of Finland (VTT), Espoo, Finland, October 2007.

[32] B. Alwerud. OL1/OL2 - RPV - TURO2018 - Structural analysis of the load cases Normal operation, ADS A and Cold start-up/shutdown. Report FSD3020506-13, Rev. 1, FS Dynamics Sweden AB, Gothenburg, Sweden, 2017-01-31.

[33] ASME Boiler and Pressure Vessel Code, Section XI. American Society of Mechanical Engineers (ASME), New York, 2015 Edition.

[34] H. Keinänen. OL2 Reactor Pressure Vessel 312 -nozzle welding residual stress computation. VTT Report VTT-R-04210-12, Technical Research Centre of Finland (VTT), 2012, Espoo, Finland. 28+6 p.

[35] O. Cronvall, OL1 and OL2 - Reactor Pressure Vessel crack sensitivity analyses 312 -nozzles, Rev. 1. Report VTT-R-04821-07, Technical Research Centre of Finland (VTT), Espoo, Finland, October 2007.

[36] D. Rudland et al. Further Welding Residual Stress and Flaw Tolerance Assessment of Dissimilar Metal Welds with Alloy 52 Inlays. Article PVP201025433, Proceedings of the ASME 2010 Pressure Vessels \& Piping Division / KPVP Conference 2010, July 18-22, 2010, Bellevue, Washington, USA.

[37] P. Dillström et al. 2008. A Combined Deterministic and Probabilistic Procedure for Safety Assessment of Components with Cracks - Handbook. SSM Research Report 2008:01, Swedish Radiation Safety Authority (Strålsäkerhetsmyndigheten, SSM). Stockholm, Sweden, 2008. 
https://www.stralsakerhetsmyndigheten.se/contentassets/490fc1bc2b2d418f83f10 bf1df5832a4/ssm-report-200801

[38] B. Alwerud. OL1/OL2 - RPV - TURO2018 - Derivation of local stresses and strains in a detailed sub model of the core shroud. Report FSD3020506-53, Rev. 01, FS Dynamics Sweden AB, Gothenburg, Sweden, 2017-01-31.

[39] E.T. Hayes. OL2 - System 21 - Assessment of the 60 Year RPV and Internals Fluence. Westinghouse Non-Proprietary Class 3 Report WCAP-18063-NP Revision 0-A, Westinghouse Electric Company LLC, January 2016.

[40] B. Alwerud. OL1/OL2 - RPV - TURO2018 - Structural analysis of the load cases Normal operation, ADS A and Cold start-up/shutdown. Report FSD3020506-13, Rev. 1, FS Dynamics Sweden AB, Gothenburg, Sweden, 2017-01-31.

[41] H. Keinänen. Computation of cladding welding stresses. Report VTT-R-0602014, Technical Research Centre of Finland (VTT), Espoo, Finland, January 2015.

[42] K. Törrönen, H. Kotilainen. TVO-1 Ydinvoima-laitosyksikön Reaktoripaineastian Referenssilämpötilan (RTNDT) Määritys. Tutkimusselostus N:o 6019-6, Valtion Teknillinen Tutkimuskeskus, Espoo, Finland, November 1976. (In Finnish)

[43] Regulatory Guide 1.99, Radiation Embrittlement of Reactor Vessel Materials, Revision 2. U.S. Nuclear Regulatory Commission (US NRC), Washington, 1988. https://www.nrc.gov/docs/ML0037/ML003740284.pdf

Otso Cronvall

VTT Technical Research Centre of Finland Ltd (VTT)

Kemistintie 3, Espoo, 02044 VTT, Finland

otso.cronvall@vtt.fi 